\section{Insulin, IGF-I and growth in diabetic rats}

SIR-Scheiwiller et al. recently presented evidence $^{1}$ that insulin, and to a lesser extent IGF-I (insulin-like growth factor I), stimulate growth in diabetic rats, and proposed "a new mechanism of endocrine control of growth", in which growth hormone $(\mathrm{GH})$ and insulin act mainly by modulating hepatic IGF-I synthesis.

It is of course well-known that diabetic animals fail to thrive and grow, an impairment which is restored by insulin treatment ${ }^{2}$. Scheiwiller et al. make no mention of an obvious explanation for their results, namely that diabetes obliterates pulsatile GH secretion, whereas insulin treatment restores $\mathrm{GH}$ secretion and with it, growth. Diabetic rats show greatly impaired $\mathrm{GH}$ secretion ${ }^{3}$. We have found that insulin treatment does restore GH secretory patterns to normal in diabetic rats, and restores growth (see figure).

Scheiwiller et al. suggested that the growth-promoting and hypoglycaemic effects of insulin and IGF-I were independent because hyperglycaemia persisted in the animals receiving all but the highest doses of insulin. In our experiments, the return of $\mathrm{GH}$ pulsatility and reductions in food intake and urine output occurred soon after insulin treatment, but well before blood sugar values fully returned to normal. Indeed, diabetic animals receiving insulin gained weight immediately owing to the early amelioration of diabetic symptoms, followed by a much more gradual increase reflecting an anabolic response. It would be interesting to learn what proportion of the 6-day body-weight increases reported by Scheiwiller et al. occurred within the first two days of insulin or IGF-I treatment. The same group has also found that insulin is an order of magnitude more potent as a growth promoter than IGF-I, by a factor which closely parallels the relative hypoglycaemic potencies of these peptides ${ }^{4}$. We agree that growth can proceed before euglycaemia is reached, so the relevant parameter may be the relative abilities of IGF-I and insulin to restore intracellular glucose transport in diabetic rats.

We propose a different explanation. Intracellular starvation blocks anabolic responses in the absence of an insulin-like substance, GH secretion is suppressed and growth is arrested. Without normal GH secretion, IGF-I levels fall. Treat- ment with insulin (or larger doses of less potent insulin-like substances) corrects intracellular metabolism, restores the ability to produce an anabolic response, restores normal $\mathrm{GH}$ secretion and allows growth to resume. The resumption of $\mathrm{GH}$ secretion raises IGF-I levels to normal. We suggest it is unnecessary to advocate new endocrine mechanisms controlling growth without properly considering the most potent old one - endogenous growth hormone itself.

\section{I.C.A.F. RoBINSON} R.G. Clark

L.M.S. CARLSSON National Institute for Medical Research, Mill Hill, London NW7 1AA, UK

1. Scheiwiller, E. et al. Nature 323, 169-171 (1986).

2. Fajans, S.S. in Endocrinology Vol. 2 (ed. DeGroot, L.J.), 1007-1023 (Grune and Stratton, New York, 1979) Tannenbaum, G.S. Endocrinology 108, 76-82 (1981) 4. Froesch, E.R. et al. J. Endocr. 111, (suppl.), 2P (1986). 5. Clark, R. G. et al. J. Endocr. 111, 27-35 (1986).

Froesch AND ZAPF REPLY-Robinson, Clark and Carlsson demonstrate very beautifully that the restoration of normalglycaemia in diabetic rats by insulin normalizes the secretory pattern of growth hormone. However, we do not agree with their view that the effects of IGF-I on growth simply reflect "insulinlike" potency and a correction of intracellular metabolism. It is accepted that the relative 'growth potency' of IGF-I differs from that of insulin by a factor of 100 or more depending on the cell type ${ }^{1}$. IGF-I in very small concentrations affects differentiation and replication of chondrocytes and calvaria cells ${ }^{2-4}$ but much larger concentrations are required for acute insulinlike effects on muscle and adipocytes'.

We would like to add the relevant data on the severity of diabetes in the different groups of rats. Glucosuria was identical in untreated diabetic rats and in growing diabetic rats treated with IGF-I $\left(300 \mu \mathrm{g}\right.$ day $\left.^{-1}\right)$ and in both groups averaged 30 g per $24 \mathrm{~h}$ per $100 \mathrm{~g}$ body weight. In the normoglycaemic insulin-treated (2.5 $\mathrm{U}$ per day) rats, glucosuria was reduced to $3 \mathrm{~g}$ per day. Body weight gain was linear over 6 days in the insulin- and IGF-I-treated groups. The severity of diabetes is also reflected by the food consumption which averaged (in g per day): 21 in untreated diabetic rats; 7 in control rats; 24 in diabetic rats treated with $300 \mu \mathrm{g}$ of IGF 1 per day; and 13 in diabetic, insulin-treated normoglycaemic rats, showing that the diabetic state was nearly normalized by

Plasma $\mathrm{GH}$ profiles in three rats before, and 2 and 7 days after, beginning a constant intravenous infusion of insulin $\left(200 \mathrm{~m} \mathrm{Uh}^{-1}\right)^{5}$.

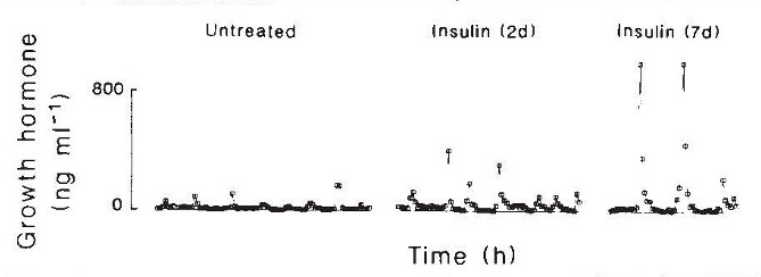

insulin but not by recombinant human (rh) IGF-I. The growth-promoting effect of either insulin or rhIGF-I does not therefore parallel the overall anti-diabetic and blood glucose-lowering potency. We conclude that IGF-treated diabetic rats are almost as diabetic as untreated diabetic rats but grow considerably despite hyperglycaemia; that the degree of stimulation of growth parameters correlates very well with serum IGF-I levels, and that IGF-I can stimulate growth of hypophysectomized rats without lowering blood sugar $^{5.6}$.

It seems to us that the question is not whether IGF-I by itself has growth-promoting activity but rather if growth hormone and IGF-I can act on growth in a concerted way. It would be interesting to infuse diabetic rats with IGF-I to find out whether IGF-I induces rat growth hormone peaks in a similar way to insulin.

E.R. FROESCH J. ZAPF

Metabolic Unit, Department of Medicine, University of Zurich,

\section{CH 8091 Zurich, Switzerland}

1. Froesch E.R. \& Zapf, J. Diabetologia, 28, 485-493 (1985). 2. Schmid, Ch., Steiner, Th. \& Froesch, E.R. Calcif. Tissue Int. 35, 578-585 (1983).

3. Schmid, Ch., Steiner, Th. \& Froesch, E.R. FEBS Lett. 173, 48-52 (1984).

4. Vetter, U. et al. J. clin. Invest. 77, 1903-1908 (1986).

5. Schoenle, E., Zapf, J., Humbel, R.E. \& Froesch, E.R. Nature 296, 252-253 (1982)

6. Schoenle, E., Zapf, J., Hauri, Ch., Steiner, Th. \& Froesch, E.R. Acta endocr. 108, 167-174 (1985)

\section{AIDS vaccine predictions}

SIR-Although most of the attempts to develop vaccines against AIDS (acquired immune deficiency syndrome) have focused on the B-lymphocyte defined epitopes of the envelope (env) protein of the human immunodeficiency virus (HIV-1) (see refs 1 and 2 ) there is a growing interest in other proteins of the virus because, for instance, patients with AIDS can die with high levels of antibody to the env protein in their blood ${ }^{3}$. Greater emphasis is therefore starting to be placed on both other proteins and the role of cellmediated immunity, particularly cytotoxic T-cells, which may provide resistance to HIV-1. T cells recognize parts of proteins (T epitopes) which are often different from B cell epitopes ${ }^{4.5}$. Thus the best candidate for a peptide vaccine might be a chain section containing both $B$ and T epitopes in regions conserved in sequence between the different isolates.

The immune response against the proteins of the gag gene might be crucial, as clinical progression to AIDS has been associated with a reduction in antibodies to gag p24, the main capsid protein ${ }^{6}$. Thus a gag p24 vaccine might prevent the onset of AIDS in HIV-1 carriers. In addition, a prophylactic vaccine might require both env and gag components.

Therefore, as shown in the figure, we 